\title{
Optimizing Solar Dish Performance Using Analytical Flux Distribution in Focal Region
}

\author{
Dany Iman Santoso ${ }^{a^{*}}$, Bambang Antoko ${ }^{\mathrm{b}}$ and Djatmiko Ichsani ${ }^{\mathrm{c}}$
}

\author{
${ }^{a}$ Department of Mechanical Engineering, State University of Surabaya, Indonesia \\ ${ }^{b}$ Department of Mechanical Engineering, Shipbuilding Institute of Polytechnic Surabaya, Indonesia \\ 'Department of Mechanical Engineering, Sepuluh Nopember Institute of Technology, Indonesia
}

\begin{abstract}
In this paper, thermal performance analysis of $4 \mathrm{~m}^{2}$ solar dish collector is presented. The focal image characteristics of the solar dish are determined to propose the suitable design of a receiver. A flat plate was used for the receiver to measure flux distribution in the focal region. The measurement had been done in the midday. Intercept factor based on this distribution had been calculated and was obtained to calculate thermal efficiency after total heat loss was described. From the experiment, total heat loss was formed by conductive and radiative in the receiver. The results showed that the increase in total heat loss followed the increase in receiver temperature and it caused a decrease in thermal efficiency. On the peak of the measurement or in midday, receiver temperature can achieve $138^{\circ} \mathrm{C}$ and it gave around 1200 -Watt heat loss and it was dominated by radiative heat loss for around $80 \%$. The thermal efficiency of the system due to flux distribution measurement in the focal region was above $70 \%$ and it was classified as high average but we needed to cover this flux up so it did not lose a lot of heat. Cavity aperture would keep around $20 \%$ total heat loss and it minimized radiative heat loss from the flux. The design of cavity aperture was the next discussion to insulate thermal heat reflection of the parabolic dish system from high radiative heat loss. (02020. CBIORE-IJRED. All rights reserved
\end{abstract}

Keywords: dish collector, focal region, receiver, flux distribution, intercept factor

Article History: Received: December 8, 2019; Revised: January 30, 2020; Accepted February 4, 2020; Available online: February 15, 2020 How to Cite This Article: Santoso, D.I., Antoko, B., and Ichsani, D. (2020) Optimizing solar dish performance using analytical flux distribution in focal region. International Journal of Renewable Energy Development, 9(1), 63-67.

https://doi.org/10.14710/ijred.9.1.63-67

\section{Introduction}

Parabolic dish collector is one of the most efficient systems for producing high temperatures heat (Reddy et al. 2015). Solar parabolic dish collector consists of three components: concentrator, cavity receiver/absorber and support structure with tracking arrangements. The performance of the solar dish collector depends on the accuracy of these components. The flux distribution in the focal region of solar dish concentrator plays a key role in the design of cavity receiver configuration. It can be predicted by optical analysis or direct measurement (Garcia et al. 2015 and Jamil et al. 2016).

The optical analysis can be accomplished either by analytical method or ray-tracing technique (Cooper et al. 2011). Some researchers used ray-tracing simulations in photovoltaic systems to give better solar position and performance (Schüler et al. 2007 and Şahin et al. 2011). Solar rays also can be simulated by LED-based optic coupler and it described relationships between light wavelength and power production by its intensity (Fortes et al. 2015). Another method called Bi-directional Transmission Distribution Function (BTDF). BTDF has been used to evaluate solar gain and daylight distribution through complex windows and shading systems (Andersen et al. 2003). This conversed ray-tracing results in BTDF values and determined in what angle of ray-tracing that gave maximum intensity. The information concerning the flux distribution in the focal plane can be used for the determination of the intercept factor of the cavity aperture.

In recent years, the use of modified cavity receivers has been suggested for application in low-cost dishes of short focal length and rather imperfect optics (Kaushika et al. 2000). The flux distribution in the focal plane may be regarded as the composition of two elliptical normal distributions. According to the concept of cone optics, the solar radiation reflected from each element of the parabolic dish would cast an elliptical image in the focal plane. Fig. 1 describes the flux mapping due to each hemisphere of the dish. There are many studies which investigate alternative cavities. Daabo et al. (2016) compared cylindrical, conical and spherical receivers (Pavlović et al. 2019). According to their results, the conical receiver is the best case among the examined. Optimization of the absorber profile and geometry is

\footnotetext{
* Corresponding author: danysantoso@unesa.ac.id
} 
carried out to improve the overall performance of the system. There are numerous designs for the absorber shape (spiral coils, cavities, tubes, etc.) during the last few years. Pavlović et al. presented a mathematical and physical model of the new offset type parabolic concentrator with a spiral coil absorber for calculating its optical performance (Pavlović et al. 2016). It is important to state that the coil geometry absorber has an optimum design in order to capture a high radiation amount with a relatively uniform distribution. Fig. 2 shows the spiral-coil absorber.
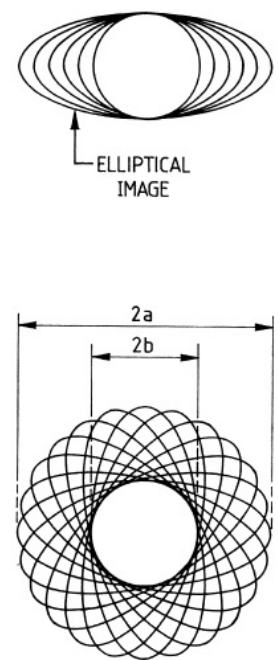

Fig. 1 The focal image of a dish concentrator

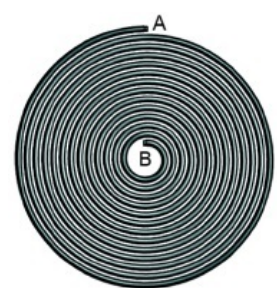

Fig. 2 Spiral-coil absorber

\section{Focal flux distribution of $4 \mathbf{~ m}^{2}$ dish collector}

\subsection{Configuration of solar dish}

A prototype of a $4 \mathrm{~m}^{2}$ parabolic dish system is built at Sepuluh Nopember Institute of Technology (ITSSurabaya) Indonesia for low-temperature application. An imperfect solar dish concentrator is referred to as a fuzzy focal solar dish concentrator. The imperfection of dish yields in spreading the focal image size and casting fuzzy focal image. The dispersion angle $\left(\delta_{\mathrm{A}}\right)$ represents the imperfection of the dish. The circular image size $\left(D_{\mathrm{i}}\right)$ in the focal plane of a solar parabolic dish concentrator is given by:

$D_{i}=\frac{4 f \tan \delta_{A}}{(1+\cos \psi) \cos \psi}$

where $\delta_{A}=\omega_{0}+\Delta \omega$ for a fuzzy focal dish; $\delta_{A}=\omega_{0}$ for a perfect optical dish error.

The amount of the dispersion angle $\left(\delta_{\mathrm{A}}\right)$ of the $4 \mathrm{~m}^{2}$ solar dish at ITS Surabaya is $0.53^{\circ}$ and the corresponding image diameter is measured $0.22 \mathrm{~m}$ at the focal plane. This makes the perfect dish because of $\delta_{A}=\omega_{0}$. Fig. 3 shows the photograph of the $4 \mathrm{~m}^{2}$ solar parabolic dish collector system at ITS Surabaya.

\subsection{Flux distribution at the focal plane}

An analytical model is developed to determine the flux distribution in the focal region of a solar dish concentrator. In this model, the central cones reflected from the two opposite halves of the dish intercept and disperse apart. The solar radiation reflected from each element of the dish would generate an elliptical image in the focal plane (see Fig.1). The outer portion of the image has an intensity that gradually diminishes to zero beyond the semi-major axis of ellipses.

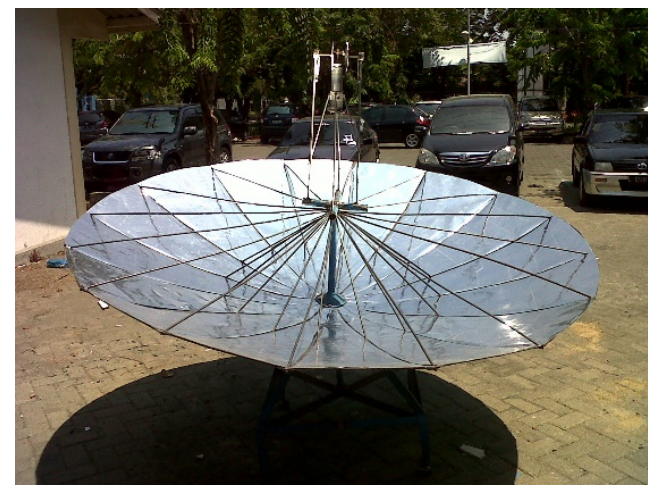

Fig. 3 A prototype of $4 \mathrm{~m}^{2}$ parabolic dish collector system developed at ITS Surabaya

The local intensity within an ellipse is taken as proportional to coverage fraction $\left(C_{\mathrm{F}}\right)$ and depends on the radial distance from the focal point. The coverage fraction is the ratio of number ellipses covering the point under consideration to the total ellipses of the same dimension $\theta /(\Pi / 2)$. The $C_{F}$ is obtained by using the equation of the ellipse and it is unity at any point within the core of any image formed by rays reflected from points on the dish.

The coverage fraction is given by:

$C_{F}\left(r_{f}\right)=\frac{2}{\pi} \sin ^{-1} R_{f} ; b \leq r_{f} \leq a$

Radial intensity distribution in the focal image of dish concentrator can be obtained by:

$I\left(r_{f}\right)=K C_{F}\left(r_{f}\right)$

The total radiation received at the focal plane is given as:

$I_{\text {image }}=\int_{0}^{a} K C_{F}\left(r_{f}\right) 2 \pi r_{f} d r_{f}$

Flux distribution of a fuzzy focal paraboloidal dish at the focal plane can be obtained with reasonable accuracy based on the determination of the optical imperfection of the parabolic dish collector in terms of dispersion angle $\left(\delta_{\mathrm{A}}\right)$. Intercept factor $(\gamma)$ is the ratio of solar radiation intercepted at the absorber to total solar radiation reflected from the concentrator. The intercept of the dish can be given as:

$\gamma=\frac{\int_{0}^{r_{0}} I\left(r_{f}\right) 2 \pi r_{f} d r_{f}}{\int_{0}^{\infty} I\left(r_{f}\right) 2 \pi r_{f} d r_{f}}$

The flux distribution is determined by measurement on the focal plane of the dish. The measurement results are symmetry and it described only in halves portion in Fig. 4. In this figure, the atmosphere temperature during 
the measurement was $34^{\circ} \mathrm{C}$ so we can know that the dish has a $0.11 \mathrm{~m}$ focal radius or $0.22 \mathrm{~m}$ focal diameter.

There is an estimation for the intensity distribution of $20 \mathrm{~m}^{2}$ fuzzy focal dish concentrator in the focal region assuming solar intensity $1000 \mathrm{~W} / \mathrm{m}^{2}$ and ideal reflecting surface $(\rho=1)$ (Reddy et al. 2015). The variation of intensity with dispersion angles $\left(\delta_{\mathrm{A}}\right)$ of $2^{\circ}, 4^{\circ}$, and $6^{\circ}$ has been estimated. The flux distribution is symmetric; therefore, only half a portion of the curve is represented in Fig. 5. The maximum intensity of the flux reduces with an increase in dispersion angle. The decrease in intensity is due to the increase of fuzziness (optical imperfection) in the dish.

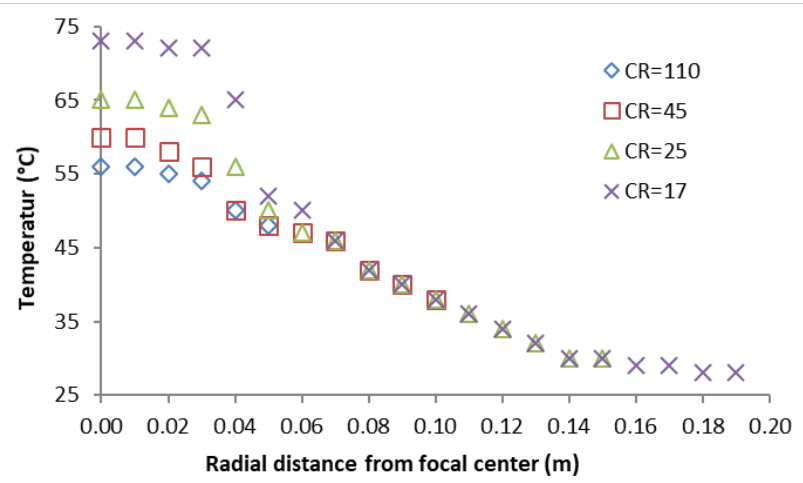

Fig. 4 Comparison of flux distribution at focal plane for different concentration ratio $\left(C_{\mathrm{R}}\right)$

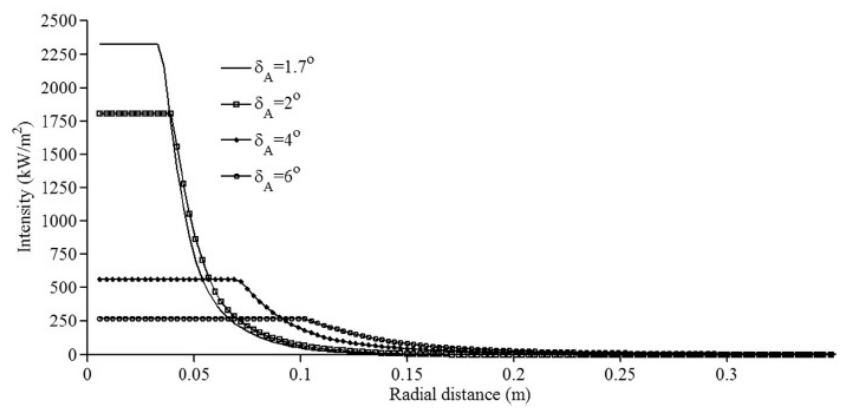

Fig. 5 Variation of the intensity of the focal image for different $\delta_{\mathrm{A}}$ (Reddy et al. 2015)

The variation of the intercept factor with radial distance from the target center of the dish is shown in Fig. 6 . This variation in the focal region is comparable with Kaushika et al (2000) calculation where the plane was located at $Z_{0}=40 \mathrm{~mm}$ and a maximum deviation of $3 \%$ was observed. The receiver had been designed as a flat plate that was placed in the focal region also the dish had $4 \mathrm{~m}^{2}$ in the area.

As a ratio in Eq. (5), intercept factor gives information about how much solar radiation can be obstructed by the receiver so it depends on the coverage factor as in Eq. (4). The intercept factor determines how much performance of the dish system before it will be reduced by some heat losses of the receiver as in Eq. (6). This was also indicated in Eq. (6) by a reduction of receiver absorptivity from $a_{\text {eff }}$ to $a$ where the value of $a_{\text {eff }}$ is greater than $a$. We have found from NASA reference publication for black copper that $a_{\mathrm{eff}}=0.98$ and $\alpha=0.78$ (Henninger 1984). Heat losses from the receiver and its impact on thermal efficiency will be discussed in the following section.

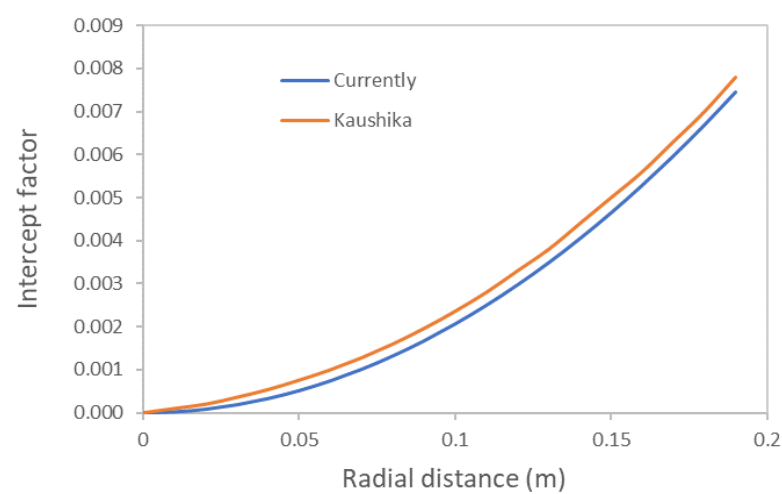

Fig. 6 Variation of intercept factor (focal plane) with radial distance

\section{Thermal analysis of receiver}

The receiver is located at the focal region to absorb the reflected solar beam radiation from the concentrator and converts it to the working fluid as thermal energy for the following process. The major feature of a receiver is to absorb the maximum amount of energy from the reflected solar beam radiation and transfer it to the working fluid with minimum heat losses. The schematic of the solar dish with a flat plate receiver is shown in Fig. 7. The thermal efficiency of the receiver is predicted by calculating the total heat losses from the receiver. The thermal efficiency of the receiver indicates the capability of the receiver to convert available solar energy into useful thermal energy.

The thermal efficiency can be given as:

$\eta_{R}=\left[\gamma \alpha_{\text {eff }}+(1-\gamma) \alpha\right]-\frac{Q_{L}}{I_{s} A_{r} \rho}$

The total heat loss rate for receiver $Q_{L}$ can be expressed as:

$Q_{L}=Q_{C K}+Q_{C C}+Q_{S R}$

Where $Q_{C K}, Q_{C C}$, and $Q_{S R}$ are conductive, convective, and radiative heat loss from the receiver respectively. The conductive, convective, and radiative heat loss is given as:

$Q_{C K}=k A_{r}\left(T_{r}-T_{a}\right) / L$

$Q_{C C}=h A_{r}\left(T_{r}-T_{a}\right)$

$Q_{S R}=\sigma A\left(T_{r}^{4}-T_{a}^{4}\right)$

We consider that there is no forced convective heat loss through the receiver because there are no significant wind velocities during the test at ITS Surabaya $\left(7.29^{\circ} \mathrm{S}\right.$, $\left.111.68^{\circ} \mathrm{E}\right)$. Also, from the construction of the parabolic dish in Fig. 7, free convective heat loss can be neglected because the receiver was in a horizontal position and with this position, there was no specific gravity effect that caused free convection heat loss to the receiver. The inclination angle from perpendicular position $\left(90^{\circ}\right)$ of the receiver was $30^{\circ}$ approximately and this did not give significant length to free convection heat transfer occurs. We used silver coating to cover the dish surface and from reference, the silver coating gives reflectivity $\rho=1$. The focal length was measured by a vertical pipe as the receiver and we searched the peak temperature at $f=0.92 \mathrm{~m}$ as the focal length of the dish. 


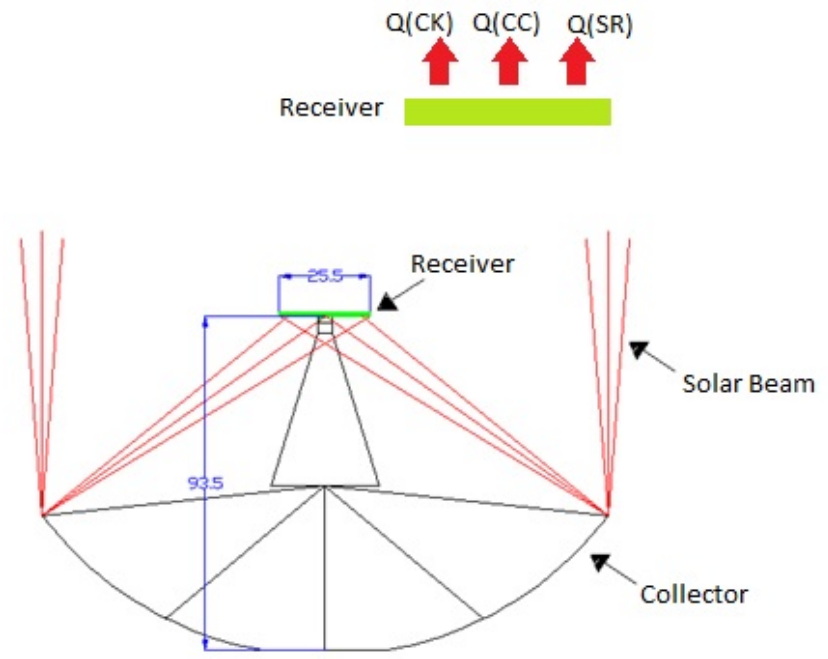

Fig. 7 Schematic of receiver for solar dish concentrator with modes of heat transfer

The measurements of receiver temperature $T_{r}$, ambient temperature $T_{a}$, and solar intensity $I_{s}$ averaged over the period of observation are summarized in Table 1. Pyranometer and infrared thermometer have been used to measure the solar intensity and receiver temperature respectively. The period of observations is in the midday. This claim is proven by the values of the receiver temperature in Table 1 that these values are almost the same at $11.00 \mathrm{am}$ and $12.30 \mathrm{pm}$. The variation of total heat losses due to the measurements have been calculated and shown in Fig. 8.

Table 1

The solar intensity and temperature measurement

\begin{tabular}{lccc}
\hline Time & $\begin{array}{c}\text { Solar } \\
\text { intensity } \\
\left(\mathbf{W} / \mathbf{m}^{2}\right)\end{array}$ & $\begin{array}{c}\text { Receiver } \\
\text { temp. } \\
\left({ }^{\circ} \mathbf{C}\right)\end{array}$ & $\begin{array}{c}\text { Atm. temp. } \\
\left({ }^{\circ} \mathbf{C}\right)\end{array}$ \\
\hline 11.00 & 840 & 40 & 34 \\
11.15 & 850 & 127 & 34 \\
11.30 & 860 & 130 & 34 \\
11.45 & 880 & 130 & 34 \\
12.00 & 900 & 105 & 34 \\
12.15 & 940 & 75 & 34 \\
12.30 & 920 & 48 & 34 \\
\hline
\end{tabular}

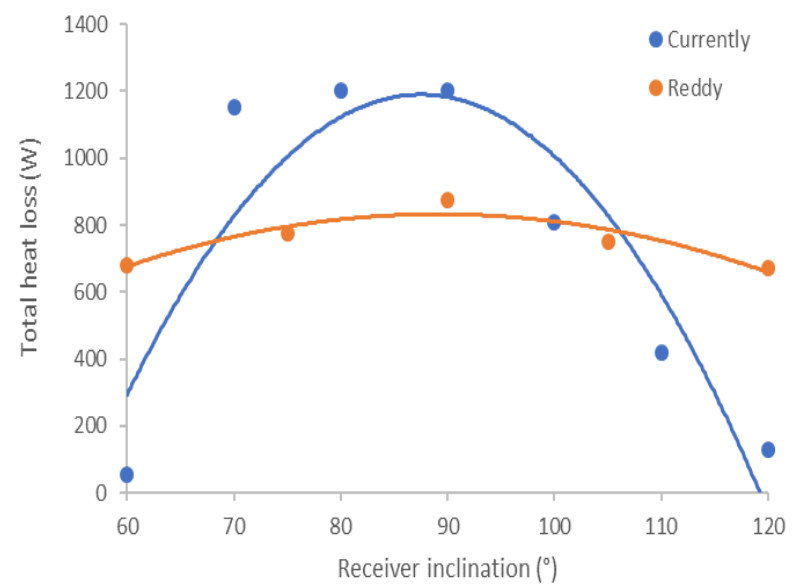

Fig. 8 Variation of total heat loss due to inclination of the receiver

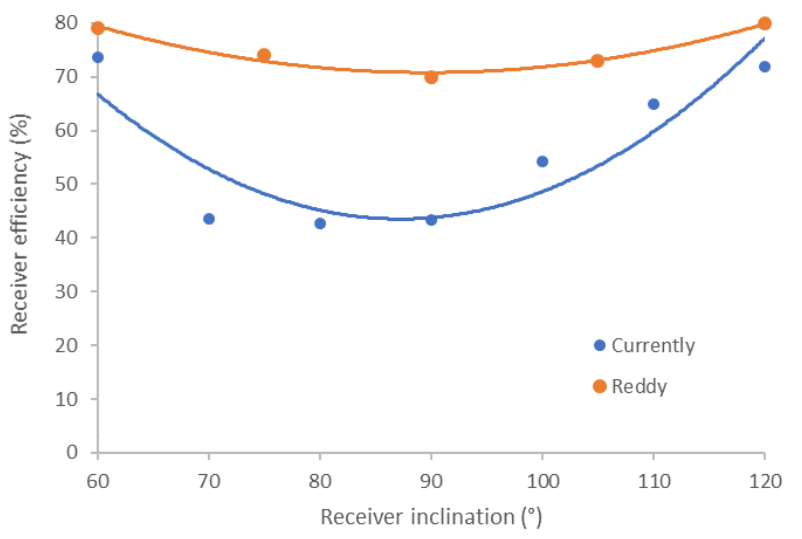

Fig. 9 Variation of the dish collector efficiency with the inclination of the receiver

The inclination angle of the receiver is measured from the solar position. For example, 90 degrees of receiver inclination is for midday where the sun is above our heads. From the graphs above, we conclude the higher receiver temperature, the higher the total heat loss. But the graph of Reddy et al (2015) gave a small slope than our experiment because they used cavity aperture to cover the receiver and this made better tools to isolate the heat. The same result was also shown by the thermal efficiency graphs as shown in Fig. 9.

Fig. 9 described the conclusion from the previous charts. The small slope for total heat loss gave a small slope for thermal efficiency. From the charts above, cavity aperture could reduce total heat loss by up to $800 \mathrm{~W}$ and thermal efficiency up to 20\%. A study about cavity aperture was conducted by (Kaushika et al., 2000; Blázquez et al., 2016; Reddy et al., 2015; Xiao et al., 2019). They investigated the better shape for the cavity aperture to minimize heat losses.

\section{Conclusions}

From the experiment, we can conclude that the better solar flux distribution in the focal region of the solar dish system due to the better concentrator construction with a small dispersion angle. Perfect solar dish system has dispersion angle the same as half angle subtended by the sun or there is no dispersion angle due to imperfection concentrator. We can design the receiver after the diameter size of the focal region was determined. We can use the spherical shape as a receiver to cover this region. The analytical results for the receiver depend on the shape of the receiver.

Based on the measurement, the solar intensity has a short time period to achieve a peak. There are just two hours averaged per day to measure the experiment data. The highest solar intensity makes the highest receiver temperature and total heat loss but it gives the lowest thermal efficiency. Receiver with cavity aperture presents a smaller slope chart than the receiver without cavity aperture.

\section{Nomenclature}

$\begin{array}{ll}a & \text { Length of semi-major axis of ellipse }(\mathrm{m}) \\ A & \text { Area }\left(\mathrm{m}^{2}\right) \\ b & \text { Length of semi-minor axis of ellipse }(\mathrm{m}) \\ C_{F} & \text { Coverage fraction } \\ C_{R} & \text { Concentration ratio }\end{array}$


$D_{i} \quad$ Image size at the focal plane (m)

$f \quad$ Focal length of the dish concentrator $(\mathrm{m})$

$h \quad$ Convective heat transfer coefficient $\left(\mathrm{W} / \mathrm{m}^{2} . \mathrm{K}\right)$

I Solar radiation $\left(\mathrm{W} / \mathrm{m}^{2}\right)$

$k \quad$ Thermal conductivity (W/m.K)

$K \quad$ Proportionality constant

$L \quad$ Vertical length of the receiver (m)

Q Heat loss (W)

$r_{f} \quad$ Radial distance of the elemental ring $(\mathrm{m})$

$R_{f} \quad$ Ratio of length semi-major to semi-minor axis

$T \quad$ Temperature (K)

$Z_{0} \quad$ Distance from base concentrator

\section{Greek symbols}

a Absorptivity of the receiver

$\beta \quad$ Receiver inclination $\left(^{\circ}\right)$

$\gamma \quad$ Intercept factor

$\delta_{\mathrm{A}} \quad$ Dispersion angle $\left(^{\circ}\right)$

$\eta \quad$ Efficiency

$\rho \quad$ Reflectivity of the dish concentrator

$\sigma \quad$ Stefan-Boltzmann's constant $\left(5.67 \times 10^{-8} \mathrm{~W} / \mathrm{m}^{2} \mathrm{~K}^{4}\right)$

$\psi \quad$ Rim angle of the dish $\left(^{\circ}\right)$

$\omega_{0} \quad$ Half angle subtended by the sun when viewed from earth $\left(0.53^{\circ}\right)$

$\Delta \omega \quad$ Dispersion of the half-reflected angle due to imperfection $\left(^{\circ}\right)$

$\begin{array}{ll}\text { Subscripts } \\ a & \text { Atmospheric condition } \\ C C & \text { Convection from receiver } \\ C K & \text { Conduction from receiver } \\ \text { eff } & \text { Effective } \\ r & \text { Receiver } \\ s & \text { Solar radiation } \\ S R & \text { Radiation from receiver } \\ t h & \text { Thermal }\end{array}$

\section{References}

Andersen, M., Rubin, M., \& Scartezzini, J-L. (2003) Comparison between ray-tracing simulations and bi-directional transmission measurements on prismatic glazing. Solar Energy, 74, 157-173.

Asselineau, C-A., Coventry, J., \& Pye, J. (2018) Exergy analysis of the focal-plane flux distribution of solar-thermal concentrators. Applied Energy, 222, 1023-1032.

Blázquez, R., Carballo, J., \& Silva, M. (2016) Optical design and optimization of parabolic dish solar concentrator with a cavity hybrid receiver. AIP Conference Proceedings, 1734, 070002.

Cherif, H., Ghomrassi, A., Sghaier, J., Mhiri, H., \& Bournot, P. (2019) A receiver geometrical details effect on a solar parabolic dish collector performance. Energy Reports, 5, 882897.

Cooper, T. and Steinfeld, A. (2011) Derivation of the Angular Dispersion Error Distribution of Mirror Surfaces of Monte Carlo Ray-Tracing Applications. Journal of Solar Energy Engineering, 133, 044501.

Fortes, M., Comesaña, E., Indalecio, G., Rodríguez, J., Otero, P., -Loureiro, A.G., \& Vetter, M. (2015) Design and Monte Carlo Simulation of a LED-based Optic Coupler. 1 $7^{\text {th }}$ UKSIM-AMSS International Conference on Modelling and Simulation, 577581.

García, L., Burisch, M., \& Sanchez, M. (2015) Spillage estimation in a heliostats field for solar field optimization. Energy Procedia, 69, 1269-1276.
-González, A.S. and Santana, D. (2015) Solar flux distribution on central receivers: A projection method from analytic function. Renewable Energy, 74, 576-587.

He, Y-L., Wang, K., Qiu, Y., Du, B-C., Liang, Q., \& Du, S. (2018) Review of the solar flux distribution in concentrated solar power: non-uniform features, challenges, and solutions. Applied Thermal Engineering, 149, 448-474.

Henninger, J.H. (1984) Solar Absorptance and Thermal Emittance of Some Common Spacecraft Thermal-Control Coatings. NASA Reference Publication, 1121.

Jamil, U. and Ali, W. (2016) Performance tests and efficiency analysis of Solar Invictus 53S - A parabolic dish solar collector for direct steam generation. AIP Conference Proceedings, 1734, 070018.

Kaushika, N.D. and Reddy, K.S. (2000) Performance of a low cost solar paraboloidal dish steam generating system. Energy Conversion \& Management, 41, 713-726.

Mao, Q., Zhang, L., \& Wu, H. (2015) Study on Concentrating Characteristics of a Solar Parabolic Dish Concentrator within High Radiation Flux. International Journal of Photoenergy, $2015,1-7$.

Nyeinga, K., Okello, D., Nydal, O.L. (2019) A ray tracer model for analysis of solar concentrating systems. Journal of Energy in Southern Africa, 30(1), 8-20.

Pavlović, S.R., Bellos, E.A., Stefanović, V.P., Tzivanidis, C., \& Stamenković, Z.M. (2016) Design, Simulation, and Optimization of a Solar Dish Collector with Spiral-Coil Thermal Absorber. Thermal Science, 20(4), 1387-1397.

Pavlović, S.R., Stefanović, P., Janković, Z.M., Bellos, E., \& Vasiljević, D.M. (2019) Daily Performance of a Solar Dish Collector. Thermal Science, 23(3B), 2107-2115.

Reddy, K.S., Natarajan, S.M., \& Veershetty, G. (2015) Experimental performance investigation of modified cavity receiver with fuzzy focal solar dish concentrator. Renewable Energy, 74, 148-157.

Şahin, D., Ilan, B., \& Kelley, D.F. (2011) Monte Carlo simulations of light propagation in luminescent solar concentrators based on semiconductor nanoparticles. Journal of Applied Physics, 110,033108 .

Schüler, A., Kostro, A., Galande, C., del Olmo, M.V., de Chambrier, E., \& Huriet, B. (2007) Principles of Monte-Carlo Ray-Tracing Simulations of Quantum Dot Solar Concentrators. Proceedings of ISES Solar World Congress: Solar Energy and Human Settlement, 1033 - 1037.

Sup, B.A., Zainudin, M.F., ZanariahShamsirAli, T, Bakar, R.A., \& Ming, G.L. (2015) Effect of rim angle to the flux distribution diameter in solar parabolic dish collector. Energy Procedia, $68,45-52$.

Wang, F. (2014) Ray-Thermal Sequential Coupled Heat Transfer ANALYSIS of Porous Media Receiver for Solar Dish Collector. Applied Mechanics and Materials, 442, 169-175.

Wang, W. (2015) Development of an Impinging Receiver for Solar Dish-Brayton Systems. Doctoral Thesis, KTH-Royal Institute of Technology.

Xiao, H., Zhang, Y., You, C., Zou, C., \& Falcoz, Q. (2019) Effects of critical geometric parameters on the optical performance of a conical cavity receiver. Frontiers in Energy, 13(4), 673-683.

Xu, J., Li, S., Ruan, Z., Cheng, X., Hou, X., \& Chen, S. (2020) Intensive Flux Analysis in Concentrative Solar Power Applications Using Commercial Camera. IEEE Transactions on Instrumentation and Measurement, 69(2), 501-508.

Yan, J., Peng, Y.D., Cheng, Z.R., Liu, F.M., \& Tang, X.H. (2017) Design and implementation of a $38-\mathrm{kW}$ dish-Stirling concentrated solar power system. IOP Conference Series: Earth and Environmental Science, 93, 012052. 